The BDJ News section accepts items that include general news, latest research and diary events that interest our readers. Press releases or articles may be edited, and should include a colour photograph if possible. Please direct your correspondence to the News Editor, Arveen Bajaj at the BDJ, The Macmillan Building, 4 Crinan Street, London N19XW or by email to bdj@bda.org

\section{Research service targets dentists}

A support service unit for researchers in the field of health and social care has recently focused its attention on the needs of dentists in an attempt ensure that their interests are fully covered by the services. RDInfo, which is funded by the Department of Health's Research Capacity Development Programme, consists of a trio of web based services providing access to details of research funding, training and advice.

RDFunding provides information on health-related research funding opportunities. There are over 1,300 funding organisations who between them offer in excess of 5,000 awards and includes organisations such as the British Association of Oral and Maxillofacial Surgeons, British Endodontic Society and British Orthodontic Society. Dentists can register for the profiling service which keeps researchers updated with the latest funding opportunities targeted to their research areas. In addition, grants can be viewed by closing date to help timetable the writing of funding application.

RDLearning provides information on post-qualification courses, workshops, short courses and conferences available to dentists. This includes not just postgraduate courses and short courses run by organisations like the British Dental Association, but also includes a wide variety of other events such as workshops on offer by the Eastman Dental Institute, the Association of Dental Implantology, and the British Society of Periodontology. RDLearning currently holds details of over 5,500 educational events and can be searched by geographical area, subject, keyword or level of qualification.

Lastly, RDDirect is a signposting service for researchers. The team will find the best possible source of information which may involve referral to one of its advisors in your local area with whom you can discuss your enquiry. Dentists who need help or advice can contact the organisation on 0113 2951122, at www.rdinfo.org.uk, or by email info@rddirect.org.uk.

\section{Engineering human facial muscle}

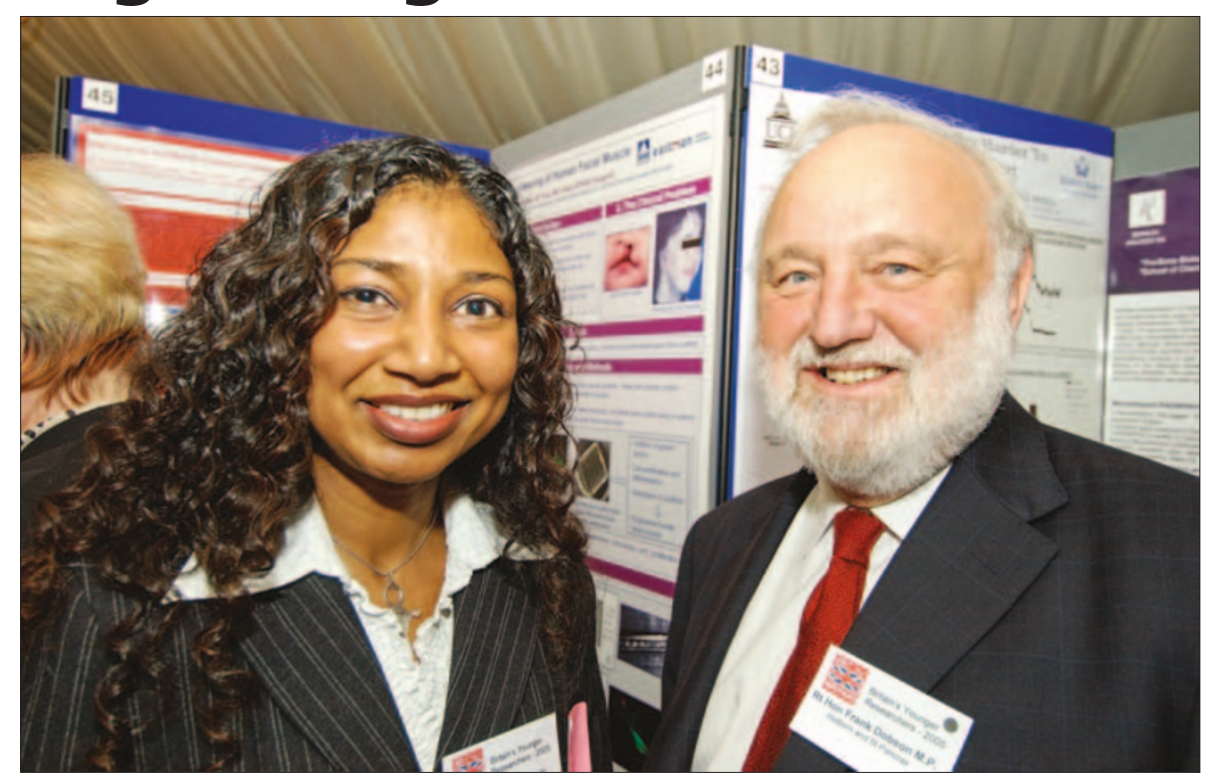

Rishma Shah, a specialist registrar at the Eastman Dental Institute, recently presented her research into investigating the use of a degradable glass fibre scaffold to engineer human facial muscle in the laboratory environment, at a House of Commons reception. For her PhD, Dr Shah is researching tissue engineering with a particular focus on human facial skeletal muscle. This is to help patients who are missing muscle tissue as a result of trauma, deformity or surgery as an alternative to the surgical transfer of muscle tissue. Cells from a patient's tissue can be grown in a laboratory and then implanted into the patient's face to replace missing tissue. In their early stages of development, the cells need another material to form a scaffold on which they can grow. The ideal is for the scaffold material to degrade by the time the cells are able to support their own growth and development. This reduces the chance of rejection when the tissue is implanted into the patient. Frank Dobson was one of the guests as he is the MP for Holborn and St Pancras, the constituency for the Eastman Dental Institute. Dr Shah said afterwards that what made her research particularly interesting was that although it related to the facial region, it could be extrapolated to other areas in the human body. Pictured above, Dr Shah (left) with MP Frank Dobson.

\section{Study reveals formula for the perfect dentist}

The factors determining the success of dental work in the UK have been revealed in a series of studies at Birmingham University. Led by Professor Trevor Burke, success was measured by how long fillings survived in patients' teeth, and the team studied factors relating to the patients, their dentists, and the time and location of where the work was carried out.

Professor Burke and colleagues found that fillings survived longer in younger than in older patients, longer for those who paid for their dental treatment than for those who received it free, and longer for those who visited the dentist rarely than those who visited often.

Looking at the characteristics of dentists, the team found that the work of older dentists lasted less well than work carried out by their younger colleagues. More experience did not appear to lead to better work and no differences were found for dentists who had qualified in any country across Europe, with all nations' dentists conducting work that had equal longevity. Whether the dentist was a man or a woman had no bearing on the quality and endurance of their work. The researchers found that fillings lasted for a shorter time today than they did ten years ago and survival was found to have nothing to do with water fluoridation, while fillings in Wales lasted significantly longer than those undertaken in England. The papers were put together in collaboration with Professor Raman Bedi and are published in the Journal of Dentistry. 


\section{Asprin reduces risks of mouth cancer in smokers}

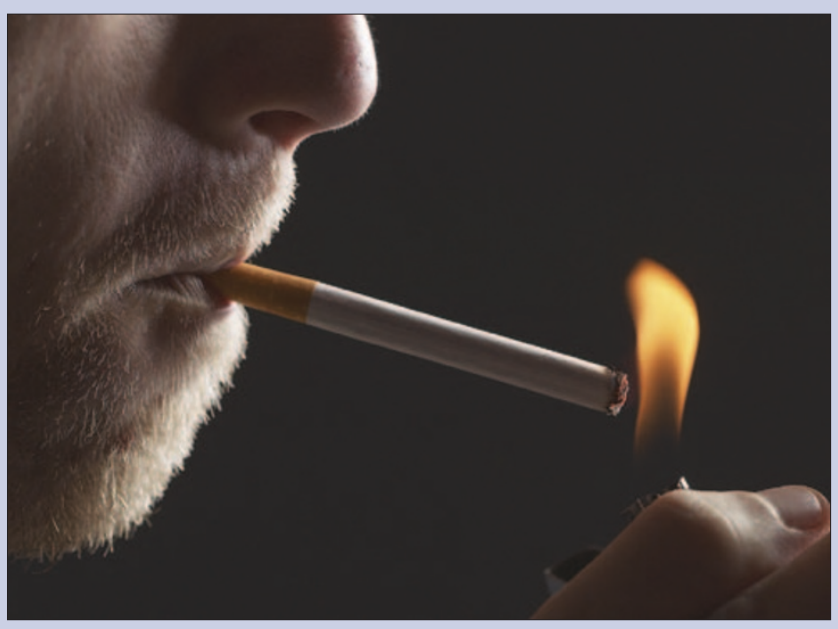

Drugs such as ibuprofen and asprin can cut the risk for oral cancer in smokers by half, new research has found.

The study analysed 20 years of data on the health of over 900 adults and found that long-term use of traditional nonsteroidal anti-inflammatory drugs (NSAIDs), such as ibuprofen and naproxen, appeared to reduce the risk of oral cancer.

However, use of these pain relievers (with the exception of aspirin) for six months or more also doubled users' risks for cardiovascular death, according to the collaborative research which was published by The Lancet.

The research team took a retrospective look at data collected prospectively from 1975 to 1995 on more than 123,000 adults participating in the Norwegian Health Survey. The survey tracked participant lifestyles, habits, and long-term health outcomes.

The team and lead researcher Dr Jon Sudbo, a senior consultant in the Department of Medical Oncology and Radiotherapy at the Norwegian Radium Hospital, narrowed their focus to 454 people with oral cancer and 454 others without such malignancies matched for age and sex. All of the individuals had a history of heavy smoking.

"Specifically, we were looking for associations between the long-term use of traditional, non-COX-2-specific NSAIDs and the risk of oral cancer, since previous work has suggested that these drugs can lower risks for other malignancies, such as colon cancer," explained co-researcher Dr Scott M. Lippman, Ellen F. Knisely Distinguished Chair and Chairman of the Department of Clinical Cancer Prevention at M. D. Anderson Cancer Center (USA).

The researchers found that adults who were prescribed NSAIDs such as aspirin, ibuprofen, naproxen, indomethacin, piroxicam and ketoprofen for six months or more (most of them for much longer periods) were at a 53\% lowered risk for oral malignancies compared with those who did not take the drugs over the long-term.

However, Dr Sudbø added that even though the drugs appeared to protect users from oral cancer, no added benefit overall in terms of prolongation of life or reduced mortality were seen. According to the study, long-term use of traditional NSAIDs, except for cardiovascular-dose aspirin, doubled users' risk for cardiovascular death.

\section{Major boost for clinical specialists}

A new awards scheme worth up to $£ 100$ million has been created which will give a major career boost to doctors and dentists who combine research or education with clinical practice. Aimed to increase the number of qualified clinical specialists going into medical research and education, the initiative is funded by the Higher Education Funding Council for England (HEFCE) and the Department of Health. The bodies will fund up to 200 new senior lectureships jointly over the next ten years.

The move follows growing concern over a drop of some 500 clinical academic staff - one in eight - between 2000 and 2004 in medical disciplines (including specialities in anaesthesia, surgery, pathology, and psychiatry) and in clinical dentistry, as reported by the Council for Heads of Medical Schools in June 2005.

In March, the UK Clinical Research Collaboration (UKCRC) sub-committee for medically and dentally qualified academics, chaired by Wellcome Trust Director Mark Walport, proposed a series of recommendations to strengthen training and progression routes to give a clearer career structure for clinical academics at all levels. The sub-committee also recommended the creation of jointly funded new senior lectureships throughout the UK for professionally qualified staff who showed considerable promise during their training. The UKCRC will co-ordinate the work of the many Government departments, hospitals, universities and charities involved in setting up and delivering the training programmes

Sir Howard Newby, HEFCE's chief executive said, "The HEFCE believe this significant investment will do much to increase the flow of excellent clinical academics into these vital roles, enhancing the long term capacity and outcomes of clinical academic research and education."

Awards will be made to the strongest applicants on the basis of a national competition and will be valid for five years. The HEFCE has pledged to contribute up to $£ 50$ million into the scheme as a 50 per cent contribution of the total for England. The Department of Health will jointly fund the scheme through local NHS trusts.

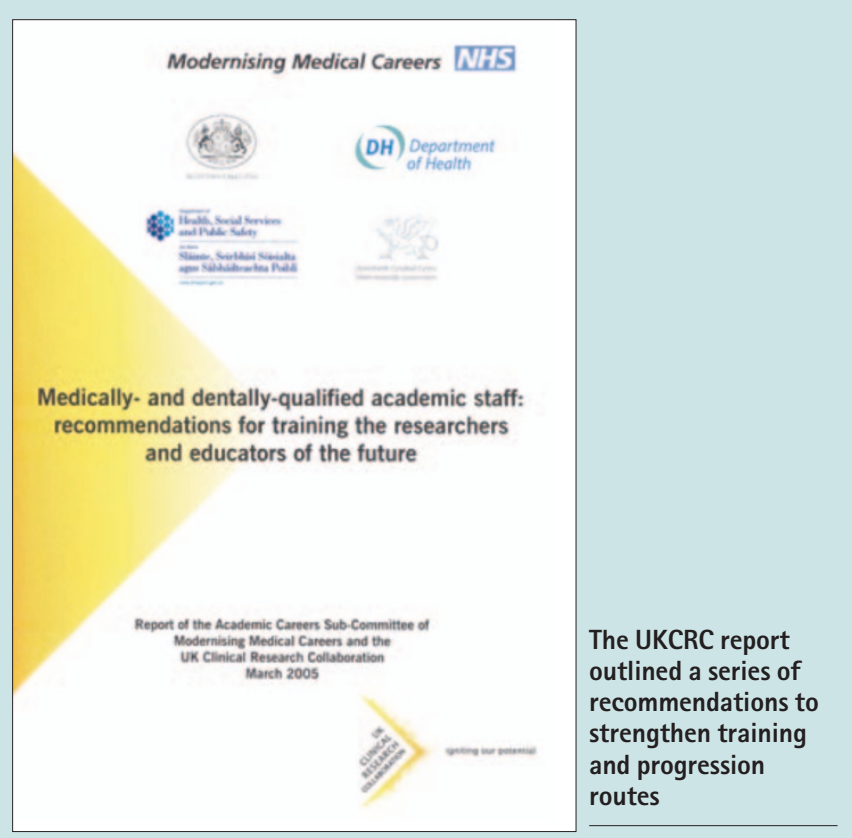




\section{Professionalism highlighted}

The General Dental Council (GDC) has produced a new leaflet for dental patients to highlight the professionalism of the dental team. 'Licensed to Practise' was launched at the Citizens Advice annual conference earlier this month, and explains the high standards patients can expect from the professionals who provide their dental care. It also offers advice on the sorts of questions patients should ask themselves when considering dental treatment.

According to Antony Townsend, GDC Chief Executive and Registrar, the aim of the leaflet is to help recognise the professionalism of the members of the dental team and help boost patient confidence. The leaflet has been introduced as a pilot to begin with and the GDC will be writing to a sample of dentists directly to offer them bulk copies for their practices.

Dental professionals who would like multiple copies of the leaflet, free of charge, for their workplace can call the GDC on 02078873824 or email communications@gdc-uk.org. It has been awarded the Plain English Campaign's Crystal Mark for clarity and will soon be available in Urdu, Hindi and Welsh.

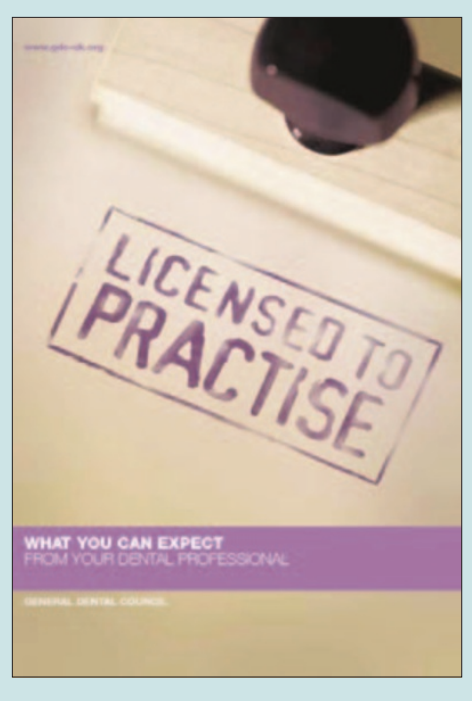

\section{Report looks into effects of antibiotic use in infancy on teeth}

Use of the antibiotic amoxicillin during infancy appears to be linked to tooth enamel defects in permanent teeth, according to a study in the October issue of Archives of Pediatrics and Adolescent Medicine.

Dr Liang Hong, of the University of Iowa, Iowa City, Chicago, and colleagues assessed the association between dental fluorosis and amoxicillin use during early childhood.

The researchers analysed data from the Iowa Fluoride Study, a prospective study investigating fluoride exposures, biological and behavioural factors, and children's dental health. They followed 579 participants from birth to 32 months, using questionnaires every three to four months to gather information on fluoride intake and amoxicillin use.

The results showed that amoxicillin use during early infancy seemed to be linked to dental fluorosis on both permanent first molars and maxillary central incisors. The duration of amoxicillin use was related to the number of early-erupting permanent teeth with fluorosis.

By the age of one year, three-quarters of the subjects had used amoxicillin and by 32 months, this had risen to $91 \%$ of participants. The study found that overall, $24 \%$ had fluorosis on both maxillary central incisors and that amoxicillin use from three to six months doubled the risk of dental fluorosis.

The significantly elevated risk for dental fluorosis associated with amoxicillin use during early infancy was found at all levels of statistical analyses, even after controlling for other potential risk factors, such as fluoride intake, otitis media infections, and breastfeeding, the authors reported.

"The findings suggest that amoxicillin use in infancy could carry some undocumented risk to the developing teeth," the authors concluded. "While the results of this one study do not warrant recommendations to cease use of amoxicillin early in life, they do further highlight the need to use antibiotics judiciously, particularly during infancy."

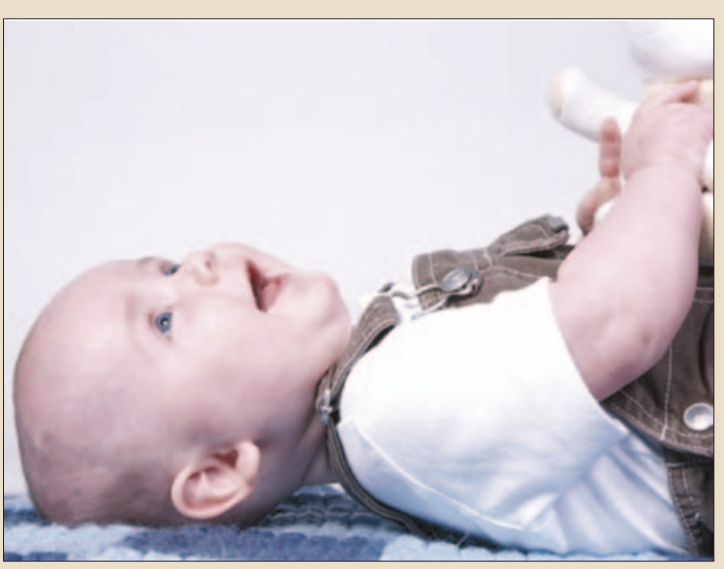

\section{DIARY}

October 2005

DenTech China 2005

Date: 26-29.10.05

Venue: Shanghai Everbright Convention \&t

Exhibition Center, Shanghai

Tel: 86-21-6294 6966

Fax: 86-21-6280 0908

Email:mail@showstar.net

www.dentech.com.cn

November 2005

British Association of Cosmetic Dentistry 2005 Conference

Date: 18-19.11.05

Venue: Victoria Plaza Hotel, London

Tel: 02076124166

Fax: 02071827123

Email: info@bacd.com

www.bacd.com

2nd European Congress on the Reconstruction of the Periodontally Diseased Patient

Date: 25-27.11.05

Venue: Radisson SAS Scandinavia Hotel, Copenhagen

Email: kongress@quintessenz.de

www.quintessenz.de/ecrp

Greater New York Dental Meeting

Date: 25-30.11.05

Venue: New York

Email: info@gnydm.com

www.gnydm.com

February 2006

2nd European Conference of Preventive and Minimally Invasive Dentistry

Date: 23-25.02.06

Venue: Congress Centre Innsbruck, Innsbruck, Austria

E-mail: kongress@quintessenz.de www.quintessenz.de/ecp

28th Asia Pacific Dental Congress

Date: 23-27.02.06

Venue: Expo Centre, Karachi, Pakistan

Email:info@apdcpakistan.com

www.apdcpakistan.com 


\section{Child protection training for dentists launched}

Dentists and their support staff are to be targeted as part of the NSPCC's biggest ever child protection training exercise. From 3 October 2005, dental surgeries across the country will receive complementary copies of EduCare, a child protection awareness distance learning programme.

The mailing is part of the NSPCC's latest initiative, 'Talk 'til it stops', a campaign designed to mobilise people to take action to end child abuse. The campaign will encourage people to talk to each other if they are worried about a child. The organisation claims that dentists can be a vital link in the child protection chain as they have frequent contact with children and families. EduCare will help dental staff recognise the possible signs of abuse and ensure they know how to act if they have concerns about a child. The programme

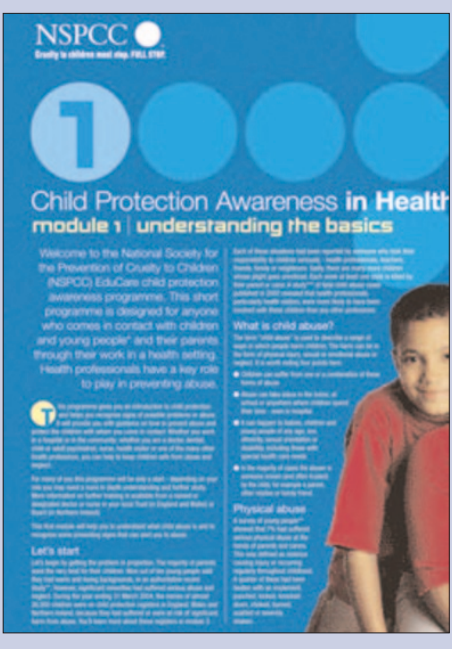
will also help staff act appropriately if a patient approaches them with child protection concerns.

NSPCC director and chief executive Mary Marsh said, "Everyone who works for or alongside children and young people must be able to recognise, respond and report any concerns they have about a child. Even professionals who have had child protection training should take this opportunity to remind themselves who the child protection leads are in their organisation and what they should do if they are worried about a child being abused."

EduCare consists of four short learning modules and is tailored for specific sectors. Recipients will receive module one which includes the learning materials and a short multiple-choice questionnaire. Participants simply read through the module, complete the questionnaire and send it off to be marked in a reply-paid envelope. As well as dentists, over 220,000 copies of the EduCare learning programme will be mailed to key groups including school and practice nurses and GPs and the police and the fire service.

During October, there are limited complimentary copies of EduCare available for anyone working with children and young people, but who have not been included in the mailing. If you would like to be part of this programme, simply register online at www.debrus-educare.co.uk/talktilitstops or e-mail your name, address and job title to talktilitstops@debrus.co.uk or telephone 01926 436202. Applicants will be processed on a first come, first served basis.

\section{Information gaps in dental services for disabled children identified}

Families with disabled children are being let down by a lack of information about dental services, according to a new report from national charity Contact a Family.

The report, Open Wide?, found that the main information providers, such as primary care trusts and NHS Direct, were unable to

\section{contact a family for families with disabled childen} The Lady Hoare Trust give families correct information for the Community Dental Service. As a result, many were forced to track down the best treatment options for their child themselves. However, once families were able to access care, most were happy with the treatment their child received. The report found that 16\% of parents had been unable to find a dentist to take their child as a regular NHS patient, 19\% had problems finding an NHS dentist who was sympathetic to the needs of disabled children and 7\% had to let their child go without treatment because they were unable to find an NHS dentist and could not afford to pay.

The survey highlighted for that many families with disabled children, accessing care at high street dental practices was simply not feasible, due to the requirement of specially adapted dental chairs and other equipment. Families seeking an NHS dentist to treat their disabled child therefore turned to the Salaried Primary Dental Care Service, which was experiencing increased vacancies in many areas leading to a patchy service for many disabled children.

Jill Harrison, Director of External Affairs for Contact a Family and author of the report, said, "Although the families we spoke to were largely satisfied with the treatment their child had received, many had experienced difficulty in finding out what services were available and where. There are also significant problems with funding of the Salaried Primary Dental Care Service, leading to severe recruitment and retention problems. Serious investment is urgently needed if it is not to be completely overwhelmed."

The organisation also called for disability awareness training for all dental care professionals, and for special care dentistry to be elevated to specialist status with the General Dental Council in order to create a skilled workforce with a specialist training pathway. Contact a Family is a national organisation that provides support, advice and information for families with disabled children. For more information or a summary of the report visit www.cafamily.org.uk.

\section{Sunshine good for teeth}

Vitamin D is just as essential as calcium for healthy teeth and bones according to a paper in the September issue of the Journal of Periodontology. This comes as good news to Americans, as daylight saving time will be extended by almost a month in the USA from 2007, which may help extend the life and health of people's teeth and bones through the extra sunshine.

According to Dr Charles Hildebolt, Department of Radiology, Washington University School of Medicine, both vitamin D and calcium counteract deficiencies and reduce bone resorption. "Studies indicate that vitamin D and calcium deficiencies result in bone loss and increased inflammation. Inflammation is a well recognised symptom of periodontal diseases, which is why it has been suggested that calcium and vitamin D deficiency may be a risk factor for periodontal diseases," he said.

According to the National Institutes of Health (USA), 10 to 15 minutes of sun exposure at least two times per week to the face, arms, hands or back is usually sufficient to provide adequate vitamin $\mathrm{D}$.

"We are not encouraging people to forego their sun protection, nor to spend prolonged periods of time in the sun," said Vincent J Iacono, DMD and President of the American Academy of Periodontology. "According to the American Academy of Dermatology, there is no such thing as a total UV block. Even the most effective sunscreens currently on the market let through enough UV to allow for adequate vitamin D formation." 


\section{GDC seeks views on new guidance for dental professionals}

What to do if worried about a colleague's professional performance and how to go about setting up an in-house complaints procedure are two of the issues covered in new draft guidance from the General Dental Council (GDC). The GDC is calling for views on two new pieces of guidance for dental professionals - 'Principles of raising concerns' and 'Principles of complaints handling'.

The documents, currently in draft, will be published next Spring and will support the GDC's core guidance for the dental team, 'Standards for dental professionals'.

The Council says that dental professionals have a duty to take action if they are worried that a colleague's health, conduct or performance, or the clinical environment, might be putting patients at risk. It hopes that its draft guidance, 'Principles of raising concerns' should encourage dental professionals to raise such matters, giving advice on what to do - when to act locally and when to involve the GDC - and points to other organisations which can offer help and advice.

It adds that draft guidance, 'Principles of complaints handling', should help dental professionals resolve complaints at a local level. It sets out good practice in complaints handling and provides a helpful checklist to refer to when setting up and running a complaints procedure.

The two draft guidance documents are posted on the GDC website at www.gdc-uk.org and the GDC is inviting comments. Please send your views and suggestions to Robin Newman email: rnewman@gdc-uk.org or write to Standards Consultation, General Dental Council, 37 Wimpole Street, London, W1G 8DQ. The closing date for responses is Friday 9 December 2005.

\section{Mechanism regulating tooth shape formulation found}

Researchers of the University of Helsinki have discovered a mechanism that regulates tooth shape formulation. One of the remaining challenges for developmental studies of mammals, whose evolution is best known from their teeth, is how their tooth shape is altered during development.

Researchers of the University of Helsinki together with their Japanese colleagues from the University of Kioto now propose a "balance of induction' mechanism directing the placement of cusps. Position and shape of cusps determine whether a tooth shape belongs to human or mouse, for example. Whereas developmental initiation of cusp formation is known to involve several developmental genes at the places of future cusps, it has remained unknown how cusps form at the right places.

Computer simulations on tooth development have suggested that there should be a gene inhibiting induction of cusps. The research team has now found this inhibitor to be a recently identified gene called ectodin, which is the first gene that is expressed as a mirror image of the future cusps.

The team generated a mouse that has no functional ectodin. Whereas the mice appear fairly normal, the areas forming cusps were much broader resulting in cheek teeth whose shape resembles more rhinoceros teeth than mouse teeth. Furthermore, these mice have extra teeth and sometimes adjacent teeth are fused. These results indicate that there is a delicate balance of induction and inhibition in determining tooth cusps and that ectodin is a key gene in this developmental control.

The team confirmed the importance of ectodin to development of teeth by culturing teeth that produce ectodin and teeth that lack ectodin with excess amounts of cusp inducing protein (bone morphogenetic protein or BMP). Whereas teeth producing ectodin develop quite normally with excess BMP, teeth without ectodin had a markedly accelerated induction of cusps. Indeed the researchers were able to induce cusps and mineralisation of teeth much faster than happens in normal mouse teeth, suggesting that tinkering with the balance of cusp induction may hold potential for future tissue engineering of hard tissues.

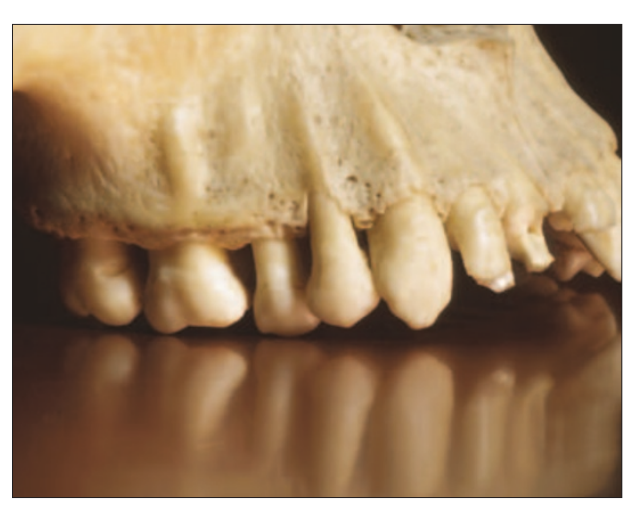

\section{Patients praise dental care}

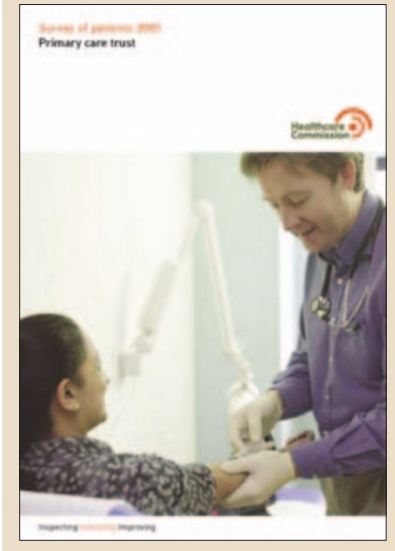

Patients give broadly positive impressions of their experience of primary care services, including care given by dentists, according to a major survey by the Healthcare Commission. The survey of almost 117,000 people sought patients' views of services provided by general practices, local health centres and dental surgeries.

With regards to dental care, many patients reported difficulties in gaining access to an NHS dentist. Around 55\% of those surveyed were registered with an NHS dentist while 69\% of those not registered with an NHS dentist said they would like to be. Nearly $80 \%$ of NHS patients fully understood the explanation their dentist gave them for their treatment or action. Of those treated by an NHS dentist, 75\% said they definitely had confidence in their dentist and 70\% said they were definitely involved in their care.

Anna Walker, Chief Executive of the Healthcare Commission, said, "This major survey of patients gives us an invaluable insight into what patients think about their access to primary healthcare and the quality of care that they receive. Although timely access to GPs and dentists is important, the quality of care that patients receive from their GP, dentist or midwife is also crucial and according to patients, it is extremely good." 